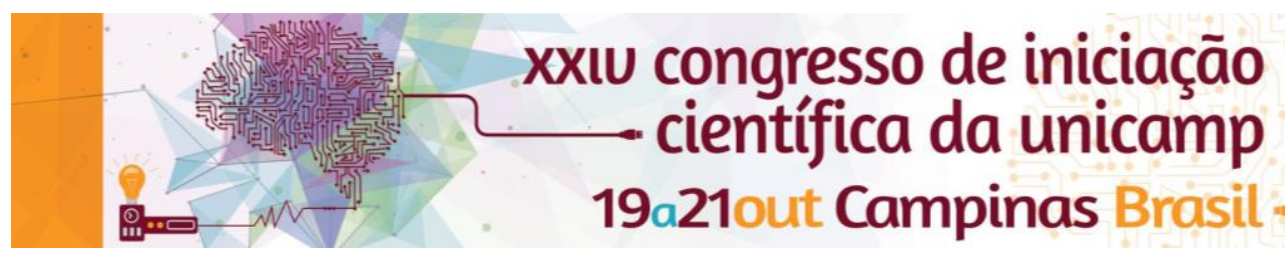

\title{
Desenvolvimento de uma ferramenta para projetos de biorrefinarias em plataforma web (módulo 1 - cana-de-açúcar)
}

\section{Mariana D. P. P. dos Santos*, Daniel de C. Assumpção, Heiko Hornung, Adriano P. Mariano}

\section{Resumo}

Este projeto teve como objetivo o desenvolvimento conceitual de uma ferramenta em plataforma web para projetos de biorrefinarias de cana-de-açúcar. A ferramenta auxiliará engenheiros do setor florestal, consultorias e estudantes na triagem rápida e preliminar de projetos conceituais de biorrefinarias.

\section{Palavras-chave}

Biorrefinarias, projetos, plataforma web

\section{Introdução}

A biorrefinaria é uma instalação que integra processos de conversão de biomassa para produção de combustível, energia e produtos químicos da biomassa. A ideia é gerar energia e, ao mesmo tempo, produzir diversos subprodutos de alto valor agregado. Desde a década de 1970, no Brasil, a cana-de-açúcar tem sido utilizada como matéria-prima para a produção em larga escala de etanol ( $1^{a}$ geração). Atualmente, busca-se aprimorar este processo, além de desenvolver novos produtos a partir da biomassa proveniente da cana-de-açúcar (bagaço) e produzir efetivamente 0 chamado etanol de $2^{\underline{a}}$ geração, tendo o bagaço como matéria-prima ${ }^{[2]}$.

Este projeto teve como objetivo desenvolver uma ferramenta web capaz de auxiliar estudantes, engenheiros, consultorias e indústrias na simulação de projetos de biorrefinarias para produção de etanol. Essa simulação consiste em utilizar diagramas de blocos dos processos além de balanços materiais e energéticos e propriedades da matéria-prima utilizada para comparar diferentes cenários de produção.

\section{Resultados e Discussão}

A simulação realizada, utilizando-se a ferramenta Excel®, baseou-se em balanços de massa e energia de biorrefinarias de cana-de-açúcar, levando em consideração parâmetros de produção, composição da cana e características termodinâmicas. Como dados de entrada (inputs), utilizou-se dados de artigos e simulações presentes nas referências ${ }^{[1][3]}$.

Como modelo a ser apresentado ao usuário, utilizou-se o diagrama simplificado abaixo de produção de açúcar e etanol.

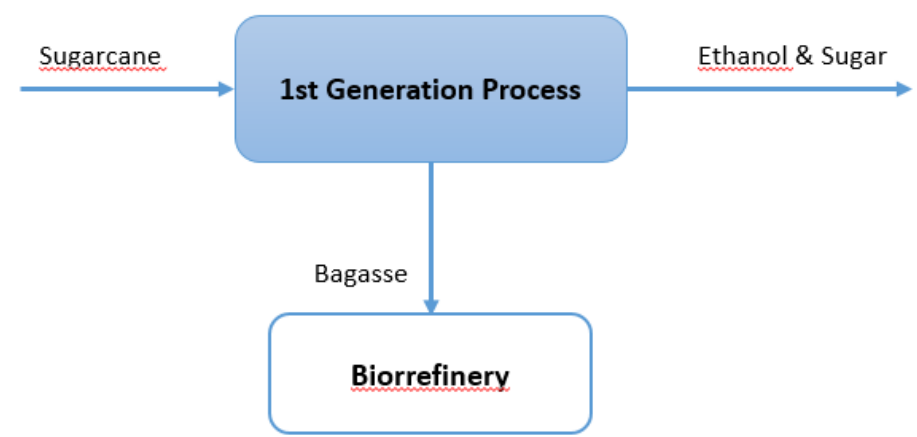

Figura 1. Representação do processo em diagrama de blocos.
Além de apresentar os resultados dos balanços (quantidades de etanol, açúcar, bagaço, vapor e energia elétrica produzidos), a ferramenta permite uma comparação entre diferentes cenários de produção. Como exemplo, a quantidade de vapor obtida, proveniente da queima do bagaço em caldeiras, varia com diferentes tipos de caldeiras a diferentes pressões de operação. A Tabela 1 abaixo apresenta um exemplo de resultado desta comparação.

Tabela 1. Comparação da quantidade de vapor produzido pela queima da mesma quantidade de bagaço.

\begin{tabular}{|c|c|c|c|}
\hline Pressão & $22 \mathrm{bar}$ & $65 \mathrm{bar}$ & $90 \mathrm{bar}$ \\
\hline Vapor produzido & $107,0 \mathrm{t} / \mathrm{h}$ & $124,9 \mathrm{t} / \mathrm{h}$ & $148,7 \mathrm{t} / \mathrm{h}$ \\
\hline
\end{tabular}

\section{Conclusões}

Por estar em fase inicial de desenvolvimento, a ferramenta limita-se a informar ao usuário os resultados referentes aos balanços realizados, além de comparar diferentes cenários de produção.

Novas funções, como simulação para a produção de etanol de $2^{a}$ geração e análise técnico-econômica, serão incorporadas ao modelo inicial ao longo do desenvolvimento do projeto.

\section{Agradecimentos}

Ao $\mathrm{CNPq} / \mathrm{PIBIC}$, pela bolsa de iniciação científica.

\footnotetext{
${ }^{1}$ Dias, M. O. de S. et al. Sugarcane processing for etanol and sugar in Brazil. Environmental Development 15, 2015, 35-51.

2 Milanez, A. Y. et al. De promessa a realidade: como o etanol celulósico pode revolucionar a indústria da cana-de-açúcar - uma avaliação do potencial competitivo e sugestões de política pública. BNDES Setorial 41 , 2015, 237-294.

${ }^{3}$ Bonomi, A. et. al. The Virtual Sugarcane Biorefinery (VSB) 2011 Report. Technological Assessment Program (PAT), 2012.
} 